\title{
Novo modelo de saúde
}

\author{
ADIB JATENE
}

$\mathrm{P}$

RETENDO FAZER não uma conferência mas uma reflexão sobre os problemas da área da saúde, procurando ressaltar os fatores que dificultam a implantação de um modelo capaz de atender às necessidades da população.

O setor enfrenta problemas em todo o mundo, independentemente do volume de recursos colocados à sua disposição. Por isso, em cada país, deve-se considerar as mudanças que ocorreram e, com base nelas, construir um modelo de assistência capaz de ser viabilizado dentro da realidade, da cultura e dos recursos de cada país.

Como ingressei na Faculdade de Medicina da USP em 1948, há 50 anos estou testemunhando e participando dessas mudanças que causaram impacto em todas as áreas, mais particularmente na da saúde.

\section{Saúde e transição demográfica}

Devo destacar, inicialmente, o que se costuma chamar de transição demográfica. Em 1950, a população mundial era de 2,4 bilhões de pessoas; hoje, aproxima-se dos seis bilhões e esse crescimento demográfico ocorreu de forma desigual nos diferentes países e continentes. A África, naquele ano, tinha cerca de 220 milhões de habitantes; hoje está com 800 milhões. A Ásia, que possuía pouco mais de 1,3 bilhão, hoje já supera a marca de 3,4 milhões. Já a Europa cresceu muito menos: passou de 400 milhões para os pouco mais de 516 milhões de habitantes agora existentes.

Enquanto a África mais do que triplicou sua população, o crescimento na Europa não atingiu 30\%. Na América Latina, o crescimento populacional foi parecido com o da África: éramos 160 milhões em 1950 e, hoje, somos mais de 400 milhões.

No Brasil, pelo Censo de 1950, tínhamos 51 milhões de habitantes; hoje, somos mais de 160 milhões. Mais do que triplicamos nossa população, e com uma agravante: daqueles 51 milhões, apenas 18 milhões moravam nas cidades; os demais viviam no campo. Atualmente, perto de 130 milhões de brasileiros moram nas cidades e pouco mais de 30 milhões na área rural. 
É importante destacar também que, na década de 50, as cidades brasileiras eram relativamente pequenas. A Grande São Paulo, por exemplo, abrigava perto de dois milhões de residentes - número que pulou para 16 milhões nos dias atuais. Já Nova York, naquela época, possuía praticamente a mesma população que tem hoje.

Essa transição demográfica tem importância fundamental nas dificuldades que enfrentamos. A população que se acumulou nas cidades é constituída, na sua maioria, por pessoas sem preparo seja educacional, seja técnico, que lhes permita competir no mercado de trabalho e, por isso, incapazes de gerar os recursos necessários para sua própria manutenção e para os equipamentos urbanos indispensáveis. Passaram a viver nas periferias das grandes cidades, onde não existe diversificação profissional e social, o que agrava ainda mais seus níveis de qualidade de vida.

Ao mesmo tempo, o perfil etário da população vem se modificando. Em 1950, a expectativa de vida ao nascer era de 47 anos; atualmente já chega a 68 anos para a mulher e 64 anos para o homem. Ganhamos, nestas cinco décadas, mais de 20 anos de expectativa de vida, ou seja, temos uma população mais idosa cujo número deve aumentar com todos os problemas que a velhice acarreta.

\section{Saúde e epidemiologia}

Outra transição pela qual o país passou nestes últimos 50 anos foi a transição epidemiológica - trazida pelo avanço científico e tecnológico. Com o surgimento de vacinas e de campanhas de vacinação em massa, moléstias transmissíveis, como a varíola e a poliomielite, foram erradicadas, enquanto o sarampo, a difteria, a coqueluche e o tétano são hoje registros marginais.

A título de ilustração, lembro que na década de 50 grande parte dos doentes internados no Instituto Emílio Ribas sofria de difteria. Na ocasião, foi feito um trabalho em conjunto com o Instituto de Cardiologia do estado (o atual Instituto Dante Pazzanese), sobre a cardiopatia diftérica. Alguém poderia dizer que, hoje, a difteria acabou no mundo inteiro. Não é verdade. Na Rússia, em 1955, ocorreram mais de 50 mil casos e, em 1966, superaram a casa dos 100 mil, com centenas de mortos, o que assustou a Europa. No Brasil, nestes últimos anos, tivemos pouco mais de 200 casos de difteria.

De outra parte, a redução da mortalidade infantil, possibilitada por essa transição epidemiológica, é também um dado importante, mesmo considerando que o índice brasileiro ainda é elevado, se comparado com o de outros países. 
Enquanto isso, e em conseqüência do envelhecimento da população, assistimos ao crescimento das doenças crônicas e degenerativas, como o câncer, a hipertensão e as cardiopatias, que demandam anos e anos de tratamento e a utilização de tecnologias que custam caro.

Sabe-se também que a mudança de hábitos, a liberação sexual, as novas fronteiras agrícolas, entre outros fatores, possibilitaram o surgimento e/ou o incremento de moléstias reemergentes, como o cólera e a dengue; e emergentes, como a aids e as causadas pelo fumo e pelas drogas. Entre outras conseqüências, esses fenômenos trouxeram uma mudança no perfil das zoonoses, ampliando ainda mais as nossas dificuldades.

Associe-se a esse quadro a violência da vida nos grandes centros causa de inúmeros assassinatos e de incontáveis acidentes de trânsito. Em 1950, a cidade de São Paulo tinha 90 mil carros; hoje são cerca de quatro milhões. A violência e os acidentes transformaram-se na segunda causa de mortalidade. E não apenas entre os paulistanos, mas no mundo todo. No nosso meio a violência urbana, com 14\%, só perde para as doenças cardiovasculares, responsáveis por 35\% do total de óbitos; o câncer figura em terceiro lugar, com cerca de $12 \%$.

\section{Saúde e tecnologia}

A outra transição que marca as últimas cinco décadas é a que chamo de transição tecnológica. Em 1950, quando cursava a Faculdade de Medicina da Universidade de São Paulo, recordo-me de quão limitados eram os recursos para se fazer o diagnóstico do paciente. Baseávamo-nos basicamente na história clínica e no exame físico. Levávamos um tempo imenso discutindo um sopro cardíaco, suas características etc. Os exames laboratoriais resumiam-se basicamente ao hemograma, à análise de fezes e urina. Havia, igualmente, uma limitação muito grande na terapêutica medicamentosa. Os medicamentos usados no Hospital das Clínicas eram quase todos preparados na sua própria farmácia. Compravam-se apenas os antibióticos que estavam aparecendo - como a penicilina e a estreptomicina - e pouca coisa mais.

Naquela época, os laboratórios farmacêuticos não tinham a força e o poder de que desfrutam hoje. A maioria dos remédios era preparada nas próprias farmácias. Nos últimos 50 anos, a mudança foi dramática. E há um acontecimento extremamente significativo, que a acelerou.

Refiro-me ao lançamento do Sputnik, ocorrido em 1957, que deflagrou a corrida espacial, quando os cientistas se viram obrigados, para o 
sucesso do projeto, a monitorar e a controlar os sinais vitais dos astronautas. A tecnologia surgida com a necessidade de controlar os sinais vitais do homem no espaço foi incorporada pela medicina, com o surgimento das unidades coronarianas, das unidades de terapia intensiva, dos monitores todos subprodutos da corrida espacial, estabelecida naqueles anos entre a então União Soviética e os Estados Unidos.

Em 1965 começamos a produzir, no Instituto Dante Pazzanese, marcapassos individuais implantáveis. Naquela época, tínhamos que ir até a rua Santa Ifigênia, para comprar componentes como o diodo e os transístores necessários. Só que não podíamos confiar naqueles componentes, fabricados para rádios e televisores. Tivemos de recorrer a componentes com especificação militar, que eram mais confiáveis. Naqueles tempos, dispúnhamos apenas de baterias de mercúrio. Hoje, contamos com avançados laboratórios de eletrônica e de microeletrônica, com o primeiro deles instalado na Universidade de São Paulo.

Em 1962 passamos a dispor da tomografia computadorizada; em 196566, do ultra-som; depois vieram a medicina nuclear, a ressonância magnética, enfim, todo um arsenal para diagnóstico absolutamente impensável há 50 anos.

$\mathrm{Na}$ área de materiais, o avanço também foi notável, com a introdução, por exemplo, dos descartáveis, dos catéteres e dos fios para suturas atraumáticas. No começo, era o fio de seda multifilamentado; depois veio o nylon, o polipropileno; as agulhas atraumáticas de 6, 8, 10 zeros, permitindo um maior refinamento nos procedimentos cirúrgicos.

Lembro-me, ainda, de quando os doutores Magaldi e Tito Ribeiro fizeram, para a nossa turma do $2^{\circ}$ ano da FM-USP, em 1949, uma demonstração do primeiro rim artificial, construído aqui em São Paulo. Era uma máquina enorme, com uma membrana de celulose enrolada. Sua aplicação era muito discutível no final dos anos 50 , quando começamos a realizar, no Hospital das Clínicas, cirurgias cardíacas com circulação extracorpórea. Um paciente recém-operado foi acometido de insuficiência renal, mas não podia ser submetido ao rim artificial antes que seu nível de potássio chegasse a 7,5 miliequivalente por litro. Quando se decidiu pelo rim artificial, o paciente teve que ser levado a um outro andar, mas morreu de parada cardíaca, ainda no elevador. Hoje, o uso do rim artificial é absolutamente comum no Brasil, com cerca de três milhões de sessões de hemodiálise por ano. A incorporação tecnológica permitiu o desenvolvimento de técnicas que culminaram com os transplantes de órgãos, hoje praticados rotineiramente. 
Como parte dessa transição tecnológica, destaquem-se, igualmente, os avanços extraordinários verificados na área dos medicamentos. Antes, grande parte das pesquisas com fármacos era realizada nas universidades e nos institutos oficiais, com seus resultados transformando-se em patrimônio da humanidade. Aqueles que utilizavam tais conhecimentos passaram a elaborar produtos os quais, comercializados, geravam retorno capaz de levar ao surgimento dos laboratórios industriais, que passaram a oferecer medicamentos dispensando a formulação, mudando o caráter das farmácias, hoje entendidas como estabelecimentos comerciais.

Os laboratórios representam um enorme poder econômico, o que lhes permite realizar suas próprias pesquisas e contratar cientistas junto às melhores universidades. Essa mudança teve imensa repercussão social. O conhecimento científico deixou de ser patrimônio da humanidade para se converter em propriedade de empresas, sob a proteção das chamadas patentes. Daí cobrarem, por seus medicamentos, preços que a grande maioria da população mundial não pode pagar.

Ressalte-se, ainda, que essas grandes indústrias não costumam priorizar as pesquisas de medicamentos para o combate de endemias do chamado Terceiro Mundo. Não vêem nos países pobres um mercado atraente. Para corroborar tal fato, lembremo-nos das pesquisas para o tratamento da doença de Chagas, que foram interrompidas, enquanto as pesquisas de remédios para a depressão, e de outros fármacos voltados para o consumo das camadas mais afortunadas da população, continuam sendo desenvolvidas.

Outro exemplo emblemático dessa distorção são os medicamentos contra a Aids, cujos preços proibitivos impedem que a maioria dos países possa adquiri-los. Quando da minha passagem pelo Ministério da Saúde, enfrentei grandes problemas para poder oferecer esses medicamentos às pessoas que se julgam no direito de recebê-los. Somos hoje, talvez, o único país a oferecer gratuitamente o coquetel para os portadores de Aids.

\section{Mudanças no ensino médico}

Ainda com referência à tecnologia, não poderia deixar de lembrar as grandes mudanças ocorridas no ensino médico. Sou do tempo em que se aprendia anatomia dissecando cadáver. Para que se tenha uma idéia de como mudou o ensino, quando dirigi a Faculdade de Medicina de Pinheiros, tivemos que montar um laboratório com freezers capazes de alojar um cadáver inteiro. Adaptamos uma serra de fita - conseguida a muito custo pelo doutor Aldo Junqueira - para que pudéssemos serrar o cadáver em fatias de $3 \mathrm{~mm}$, colocadas entre duas placas de acrílico para ensinar anatomia de modo 
a entender os cortes obtidos pela tomografia computadorizada e ressonância magnética.

Todos esses avanços tecnológicos aconteceram num crescendo, ao ponto de nos defrontarmos hoje com o bebê de proveta, que nos leva a uma indagação de ordem ética. $\mathrm{O}$ que fazer com os embriões que não são implantados? Devemos simplesmente destruí-los?

É evidente que todos esses avanços trouxeram enorme elevação dos custos na área da saúde, o que, em parte, explica a transição assistencial. Antes, tínhamos as Santas Casas, que cuidavam dos mais necessitados e serviam, inclusive, de asilo para os indigentes. Eram poucos, então, os hospitais privados, como também eram escassos os recursos terapêuticos e os instrumentos para diagnósticos mais precisos. Ao lado das Santas Casas começaram a surgir os hospitais públicos que, com o passar do tempo, assumiram a predominância no atendimento, por serem gratuitos e também por estarem melhor aparelhados. O Hospital das Clínicas, criado em 1944, recebeu equipamentos que o transformaram num centro avançado e receptor de pacientes de todo o Brasil, e até de países vizinhos. Os hospitais privados não estavam preparados para cuidar dos casos mais complexos e que necessitavam de recursos mais avançados. Esses pacientes eram encaminhados ao Hospital das Clínicas e rotulados como de interesse científico.

Em meados dos anos 50, sob a era Kubitscheck, o Brasil passou a experimentar um grande surto de desenvolvimento econômico, graças à chegada da indústria automobilística, da indústria naval, da abertura de estradas e da construção de hidrelétricas, culminando com a implantação da nova capital no país. Com isso, despertou-se, também, uma preocupação maior com a assistência médica aos trabalhadores. Foi nessa época que surgiram os primeiros grupos de medicina, a chamada medicina de grupo. Depois vieram outros modelos, como as cooperativas médicas, o seguro saúde, os planos de saúde, a autogestão, que resultaram em profunda mudança na área do atendimento médico. Os hospitais privados foram se capitalizando, passaram a se atualizar e a investir em novos equipamentos, ao mesmo tempo em que os hospitais públicos viram seus orçamentos se reduzirem e, com isto, diminuir sua capacidade de investimento.

Quando passei pela Faculdade de Saúde Pública aprendi, na cadeira de Administração Hospitalar, que além de recursos de custeio, um hospital precisa de outros $2,5 \%$ por ano, do valor atualizado do prédio, para obras de reparos e reformas; e outros $10 \%$, no mínimo, do valor atualizado dos equipamentos para a aquisição ou troca da aparelhagem. Um equipamento hospitalar não dura mais que dez anos. Nossos hospitais públicos, vitima- 
dos pela forte compressão de gastos a que foram submetidos por anos seguidos, acabaram, na maioria dos casos, cedendo seu lugar a hospitais privados, como centros de excelência em tratamento. Como conseqüência de todas estas transformações os médicos, em sua maioria, foram progressivamente sendo transformados em assalariados, o que os obrigou a trabalhar para duas ou mais instituições ao mesmo tempo, como forma de obter uma remuneração mais condizente. Rompeu-se, assim, o vínculo entre quem presta e quem recebe o atendimento e, em conseqüência, a responsabilidade de quem presta para com quem recebe o atendimento.

O avanço tecnológico trouxe ainda a fragmentação do profissional médico, com o surgimento dos chamados especialistas. Hoje, quando uma pessoa tem um problema de saúde qualquer, ela procura saber qual especialista deve procurar. Não existe mais aquela figura do médico de família, que acompanhava a pessoa ao longo da vida, que a tratara em doenças anteriores, que conhecia sua família, que sabia onde ela morava e no que trabalhava. Agora, ela tem de se tratar com o especialista, que pode até recebê-la bem e pontualmente, mas com quem não guarda laços maiores. O especialista, no fundo, é um terapeuta: cuida de uma determinada doença, surgida num determinado momento, mas não mantém um relacionamento duradouro com o paciente. A perda desse vínculo e dessa responsabilidade transformou médicos em técnicos. E há uma diferença muito importante entre o médico e o técnico. $\mathrm{O}$ médico trata de pessoas com suas preocupações, aflições, medos e inseguranças. Já o técnico preocupa-se mais com a doença, e menos com a pessoa do doente.

\section{Saúde e meio ambiente}

Nas últimas cinco décadas presenciamos, igualmente, ao que chamo de transição ecológica. Quando se fala em ecologia, nos vem à mente quase sempre a importância da preservação das florestas. Entretanto, devemos nos preocupar, também, com as questões ecológicas levantadas pela urbanização - a poluição do ar, do solo, da água; o excesso de resíduos industriais e de dejetos humanos lançados nos cursos d'água. Como resultado, vimos o Tietê e outros rios que cortam a nossa cidade transformados em caudais de esgotos a céu aberto.

Como todos sabemos, a poluição do meio-ambiente provoca sérias lesões à saúde. Saúde, na definição da OMS, é uma situação de bem-estar físico, psíquico e social. Não melhoraremos jamais os nossos índices de sanidade se não cuidarmos, atenta e desassombradamente, das águas, dos esgotos, da habitação, da alimentação, da destinação final do lixo, do lazer, 
do salário, da qualidade do alimento e do medicamento, da imunização e do combate às endemias, da vigilância sanitária e, evidentemente, do diagnóstico e do tratamento das doenças.

A deterioração do meio-ambiente, seja urbano ou rural, é algo da maior gravidade. No Brasil, cerca de $90 \%$ da população urbana já se abastece de água encanada e tratada. Entretanto, o fornecimento regular, sem intermitência, atinge apenas $60 \%$ dessas pessoas. Sabemos que, quando se interrompe o fluxo de água pelos encanamentos, surge o risco da contaminação. Quanto à coleta de esgotos, nossos domicílios urbanos atendidos não passam de $60 \%$ do total. E o mais grave: apenas $8 \%$ dos esgotos coletados são tratados.

As estatísticas sobre o lixo revelam que cerca de $80 \%$ são coletados nas cidades, mas mais da metade despejado em lixões a céu aberto, com a proliferação de vetores na água de chuva que se acumula em pneus, frascos e latas vazias que compõem parte desse monturo. Não surpreende, pois, a volta de doenças como a dengue. Já a tivemos, já a eliminamos, mas ela teima em ressurgir. Quando estivemos no Ministério da Saúde, propusemos um programa para erradicar o aedes egypti em 2.400 municípios brasileiros. Fomos à Organização Panamericana da Saúde e conseguimos o apoio da entidade para um programa contra a dengue, que abrangesse a América do Sul, além da América Central e da América do Norte, que também começam a ter problemas com a doença.

Levada ao presidente da República e a seu Ministério, a proposta transformou-se em projeto de governo. Criou-se, por decreto, a Comissão Executiva Nacional de Erradicação da Dengue. A proposta previa, para março de 97, o lançamento de uma campanha nacional que iria ser deflagrada no mesmo dia nos cerca de 2.400 municípios, onde havia registros da presença do mosquito transmissor. Prevíamos uma verdadeira operação de guerra ao inseto, para evitar a anunciada, e concretizada, volta da epidemia. Já estamos em 98, e a campanha que deveria estender-se por três anos resumiu-se a uma atuação pontual. Esperava-se a ocorrência de casos nos municípios para, só então, socorrê-los, ao invés de se partir para a erradicação total do mosquito. O programa previa gastos da ordem de $\mathrm{R} \$ 4$ bilhões, significativa parte dos quais deveria provir da CPMF - a Contribuição Provisória sobre Movimentação Financeira.

\section{Condições de vida}

Ao lado desses cenários criados pelas transições a que me referi, avulta o grande problema da pobreza, que não é apenas brasileiro, mas mundial. 
Tentei entender o que seria o índice de Gini, mas acabei descobrindo um outro referencial, bem mais simples e mais claro. Basta dividirmos a renda apropriada pelos $10 \%$ mais ricos da população, pela renda apropriada pelos 40\% mais pobres, para que se obtenha o índice de distribuição de renda, e em conseqüência, a extensão da pobreza de um país. Em nações como a Holanda, a Bélgica e o Japão, esse índice equivale ao número um, ou seja, os $10 \%$ mais ricos da população desses três países ficam com cerca de $22 \%$ da renda nacional, cabendo aos $40 \%$ mais pobres uma porcentagem praticamente idêntica. Na Alemanha, o índice é 1,2; nos Estados Unidos e no Canadá, 1,4; na França, 1,6; na Argentina, 2,5; na Colômbia, 3,9; no México, 4,1; no Peru, 6,1; e, no Brasil, 7,2. Esses são dados de 1995, publicados pela imprensa, segundo os quais, os $10 \%$ de brasileiros mais ricos se apropriam de pouco mais de $50 \%$ da renda nacional, enquanto os $40 \%$ da população mais pobre ficam com apenas $7 \%$.

$\mathrm{Na}$ estratificada população brasileira temos parcelas de pessoas com renda per capita superior a US\$ 25 mil por ano, o que lhes possibilita morar bem, comer bem, freqüentar restaurantes, ter carro importado e viajar para o exterior. Já os $40 \%$ mais pobres, com renda per capita anual de US\$ 800 , sujeitam-se a morar mal, a comer mal, a andar de ônibus quando podem, e a ter dificuldade para arranjar emprego.

Se considerarmos os $20 \%$ mais ricos e os $20 \%$ mais pobres da população, a situação se torna ainda mais dramática, com o nível de renda destes caindo para US\$ 250 per capita ao ano. Entre esses dois estratos, teríamos $60 \%$ de pessoas da classe média sendo empurradas para a riqueza ou para a pobreza. Costumo dizer que, num país no qual a classe média está sendo empurrada para a pobreza, a situação se complica, e muito. As revoluções que conhecemos na História nunca foram feitas pelos ricos, que usufruem sempre e em qualquer sistema; ou pelos pobres, que não têm capacidade de mobilização e organização.

Nas discussões que mantive quando da minha passagem pelo governo, eu dizia ao pessoal da área econômica que eles estavam muito acostumados a lidar com a riqueza, pois quando vêm a São Paulo, os ministros da Fazenda e do Planejamento não vão à favela aqui ao lado da USP. Vão a almoços na Fiesp, na Febraban, na Federação do Comércio. Convivem com a riqueza e, com o tempo, acabam tendo dificuldades para entender os problemas da pobreza.

Os profissionais da saúde, todos eles, convivem com a pobreza desde os seus tempos de faculdade. Por isso, não aceitam as limitações que a área econômica impõe ao setor. E não aceitam, por uma razão: para todas as 
atividades, cada qual vive de acordo com sua renda, uns usufruindo de todo o conforto e comodidade, outros no extremo oposto, enfrentando todas as dificuldades e limitações. Mas todos se adaptam ao seu nível de vida dentro das disponibilidades que possuem. Tal fato só não ocorre no setor da saúde. Diante da doença, tanto para os mais ricos quanto para os mais pobres, excluindo-se a hotelaria, o gasto é igual. Os procedimentos, medicamentos, próteses etc. são os mesmos e, como a capacidade de enfrentar os gastos é desigual, cria-se um enorme problema.

\section{A questão orçamentária}

No Brasil, 25\% da população têm planos de saúde, gastando em média ao redor de R\$ 60/mês, enquanto os demais 75\%, que dependem do sistema público, computando gastos integrados pelos setores federal, estadual e municipal, não tem, para as mesmas atividades, mais que R 7 por mês. Essa enorme disparidade de suporte financeiro gera deficiências insanáveis no setor público, particularmente dentro do modelo hospitalocêntrico a que fomos levados. Recentemente, a televisão mostrou um hospital no Rio de Janeiro onde morreram crianças no berçário. Isso ocorre, em parte, devido ao excesso de lotação. Um hospital não pode ter índice de ocupação superior a $80 \%$ dos leitos, para permitir limpeza, desinfecção etc. A unidade de neonatos daquele hospital com 12 leitos tinha 23 crianças internadas. Vimos pela televisão dois bebês em um leito sendo ventilados por um único ventilador, a cuja saída se adaptara um conector em forma de Y. Por isso, quando sugerem que o Ministro da Saúde deve fiscalizar problemas desse tipo, respondo que melhor seria mandar os Ministros do Planejamento e da Fazenda para tal incumbência.

O Ministério da Saúde, em 1995, executou um orçamento de R\$ 14,899 milhões, considerado insuficiente para, pelo menos, corrigir os valores de julho de 94 quando se iniciou o plano real. Tanto que nos dispusemos a batalhar para obter novos recursos, que se somassem, em 96, ao que tínhamos no orçamento de 95, corrigidos em valor real. Estimava-se aprovar a CPMF até outubro de 95, o que permitiria a arrecadação de cerca de R 6 bilhões em 96. Deveríamos ficar, portanto, com R\$18,613 milhões, corrigido pela inflação de $25 \%$ apurada pela Fipe, mais os R 6 bilhões de arrecadação da CPMF, o que elevaria o orçamento para R \$ 24,750 milhões.

Tal montante permitiria não só atualizar os valores de julho de 94 no atendimento médico ambulatorial - corrigindo as distorções, por exemplo, dos ridículos R 2,40 para a consulta médica - mas também ampliar o combate às endemias - particularmente a malária e a dengue - e deflagrar 
o programa de saúde da família e dos agentes comunitários com impacto sobre a mortalidade materna e infantil.

Para minha surpresa, o orçamento para 96 previa $\mathrm{R} \$ 20$ bilhões dos quais R\$ 6 bilhões deveriam vir da CPMF, cuja aprovação foi retardada de um ano, com início de sua arrecadação apenas em 97.

Nestas condições, passamos a um orçamento de R\$ 14 bilhões em 96 , inferior em valor nominal do que se gastou em 95 e insuficientes para atender minimamente às ações da saúde.

Ressalte-se que, em 95, deflagramos forte combate a fraudes e irregularidades, formulando críticas ao sistema de processamento das contas hospitalares, reduzindo de 15 para 12 milhões o número de internações.

Como na lei de Diretrizes Orçamentárias havia artigo prevendo que eventual frustração da arrecadação de CPMF seria coberta com recursos do Fundo de Estabilização Fiscal, aceitamos reduzir as despesas em nível inferior, em valor real, ao que gastamos em 95. Ficamos, assim, com cerca de R \$ 3 bilhões a serem cobertos pelo FEF, o que não ocorreu. Por isso, buscamos recursos do FAT, restando R \$ 1,8 bilhão não repassados para 97 e a dívida total seria paga com a arrecadação da CPMF. Como o orçamento de 97, incluindo a CPMF, foi de R\$20,425 milhões e a execução foi de R\$ 18,5 milhões, excluindo-se os R\$ 3 bilhões de dívida, ficamos com orçamento efetivo, em valor real, inferior ao de 95, esterilizando completamente a CPMF como recurso adicional e impedindo qualquer perspectiva de cumprimento das metas previstas quando da sua aprovação.

Tenho a esperança de que o ministro José Serra - um economista que quando esteve no Ministério do Planejamento não se manifestava sobre a CPMF, mas se opunha à sua vinculação à Saúde - lute, agora, para que isso venha a ocorrer. Minha expectativa, e pela qual tanto me bati, é que o ministro, com um destino político pela frente, não aceitará as limitações que me foram impostas, bem como ao meu sucessor.

É interessante notar que recursos criados sob o argumento de ajudar o setor da saúde, depois de aprovados, passam a ter outro destino. Em 1992, tive uma polêmica pelos jornais com o jurista Ives Gandra Martins, a propósito da Cofins - Contribuição para o Financiamento da Seguridade Social. E lutamos para que o Supremo Tribunal Federal considerasse constitucional sua cobrança. Nosso argumento básico era de que essa contribuição se destinava à Saúde. E o que aconteceu com a Cofins? Em 95, recebemos $58 \%$ do que foi arrecadado, mas em 98 o índice caiu para $24 \%$. Já com a CSLL - Contribuição sobre o Lucro Líqüido das empresas -, 83\% 
desse imposto destinaram-se à Saúde em 95, contra os 27\% de 98. Alegouse que, com a CPMF, a Saúde não precisaria mais de outras fontes de recursos; que o setor gastava mal e não havia conseguido pôr fim à corrupção. A CPMF foi proposta como recurso adicional e provisório, enquanto não se fizesse a reforma tributária, e nunca como recurso substitutivo das fontes de que o Ministério dispunha.

\section{O combate à corrupção}

A verdade, porém, é que o setor da Saúde vem sendo desfinanciado. $\mathrm{E}$, no seu quarto ano de mandato, o presidente não tem o direito de falar em corrupção. Essa é uma tarefa da oposição. O presidente tem de dizer, sim, o que foi feito para combater a corrupção - e no Ministério da Saúde se fez muito. Reduzimos de 15 para 12 milhões o número de internações pelo sistema SUS; efetuamos o levantamento de toda a rede de produtos farmacêuticos; fechamos perto de 200 laboratórios, alguns deles fantasmas; verificamos a qualidade do sangue nos hemocentros, com muitos deles sendo lacrados. O que fez o governo Fernando Henrique Cardoso para combater a corrupção no setor da Saúde não tem paralelo em outras administrações. O ralo não é a Saúde. Os ralos são a previdência pública e privada e o serviço da dívida. Aí é que estão os grandes buracos da União.

Com esse pano de fundo, pode-se perguntar: o que fazer? Alguns preferem sentar na beira do passeio e chorar; outros, acham que o importante é falar mal e reclamar. Para mim, o importante é achar a saída, construir um modelo diferente - o que está sendo trabalhado no próprio $\mathrm{Mi}$ nistério da Saúde.

O novo modelo tem origem no seio da população com a criação do agente comunitário de saúde. $\mathrm{Na}$ área onde o projeto vai ser implantado, inicialmente levanta-se o número de casas ou o de famílias. Dependendo da concentração da população, agrupam-se entre 150 e 250 famílias. Entre seus habitantes, seleciona-se alguém que more no local há pelo menos dois anos para ser treinado como agente comunitário de saúde. Ele passa a visitar as famílias, pelo menos uma vez por mês. Cadastra os moradores, verifica as doenças existentes, identifica as gestantes e observa se está fazendo pré-natal, controla a caderneta de vacinação das crianças e colabora ensinando medidas higiênicas etc. A cada cinco agentes comunitários agregase uma equipe de saúde da família constituída por um médico, uma enfermeira e uma auxiliar de enfermagem. Os membros da equipe não precisam morar na área onde atuam mas, obrigatoriamente, trabalhar em tempo integral no posto e visitar as casas indicadas pelos agentes. 
A cada 20 equipes de saúde da família instala-se um ambulatório com doze especialidades, incluindo odontologia e saúde mental. Desta forma, se restabelece o vínculo e a responsabilidade fundamentais ao atendimento adequado das pessoas. Os hospitais funcionam como referência nos casos que necessitarem de internação.

O modelo instala-se com parcerias do poder público com entidades da sociedade, com personalidade jurídica capaz de celebrar convênios e assumir a sua administração. Esse aprimoramento do PACS e do PSF do Ministério é adaptação adequada para áreas metropolitanas. Há outros modelos sendo implantados no país, como o de Niterói, centrado não no agente mas no médico de família. Todos esses esforços empreendidos pelo setor público são, na essência, a proposta do SUS.

\section{O público e o privado}

Eu sempre digo que temos, no serviço público, um corpo técnico de primeira qualidade; que as irregularidades, em geral, nunca estão relacionadas com os funcionários de carreira, mas com os que se agregam na administração ocupando funções gratificadas.

Muitos querem usar a lógica do serviço privado no serviço público, o que é uma tolice. No setor privado, a cúpula é permanente. Ela traça objetivos de longo prazo e cuida para que sejam atingidos, senão perdem patrimônio. No serviço público ocorre o contrário: a cúpula é transitória. $\mathrm{Na}$ atual administração, em pouco mais de três anos, já tivemos três ministros da Saúde. Se um traça os objetivos de longo prazo, seu sucessor, ainda que do mesmo partido, resolve mudar, e continuamos sob a recorrente descontinuidade administrativa a que nos habituamos. Os cargos de responsabilidade na administração pública deveriam ser estáveis. Na França, quando Giscard d'Estaing, um conservador, perdeu a eleição para François Mitterrand, um socialista, não aconteceu quase nada. Porque, na estrutura francesa do serviço público, os funcionários que têm de dizer "não" são estáveis. Isso é um Estado de verdade.

No Brasil, quando um ministro ou um secretário é substituído, o novo ocupante tira os cargos das pessoas que têm a responsabilidade de dizer "não". E coloca quem? Se for um político, coloca quem o ajudou na campanha. Isso me remete a uma reflexão que andei fazendo: a de que o poder não está nas mãos de quem ocupa o cargo, mas nas de quem financia as campanhas dos que ocupam os cargos. E, não é por acaso, que também sustentem a mídia, já que não acreditam em opinião pública, mas em opinião publicada. E quem controla a opinião publicada, controla a opinião 
pública. Deriva daí a força que os marketeiros vieram a assumir nas campanhas políticas.

Quando secretário da Saúde de São Paulo, eu dizia que o grande problema do pobre não era ele ser pobre, mas ter amigos também pobres. Ele não tem amigo que fala com quem decide, que marca uma audiência, que faz um projeto, que negocia um financiamento.

O problema maior que enfrentamos nos dias de hoje é saber o tipo de sociedade que queremos, se movida por interesses, ou se movida por valores. Se queremos uma sociedade solidária e fraterna, ou uma sociedade egoísta, do salve-se quem puder. Sabemos que uma sociedade muito desigual acaba gerando a decadência social. Afrouxam-se os princípios éticos. Passa-se a aceitar tudo o que interessa ao individualismo e a rejeitar tudo o que o prejudica.

Temos visto pelos jornais campanhas contra os impostos; dizem que o país não agüenta mais tanta carga tributária. Mas quem paga imposto, quem reclama do imposto, são os que concentram renda. É preciso que se entenda esse fato para que a situação não fique ainda mais complicada. A decadência social gera violência. Os ricos, que são os únicos que podem contribuir efetivamente para os cofres públicos, já circulam em carros blindados, cercados por segurança; moram em casas de muros altos, protegidos por guardas, guaritas e grades. Mas não estão seguros.

Essa não é a sociedade que queremos construir. Temos que reformulála. E o setor da Saúde mostra isso com muita clareza, no momento em que se põe 23 bebês numa unidade hospitalar em que só cabem 12. Ninguém parece interessado em ampliar essas instalações, em oferecer às pessoas de baixa renda o mínimo a que elas têm o direito. A Constituição de 88 está correta em seu capítulo sobre a Saúde, que nasceu de uma discussão que vinha sendo travada há décadas. E a Universidade tem um papel muito importante a desempenhar, na formulação e na solução de todos esses problemas. Mas é preciso, também, que cada um de nós diga: "Eu vou ajudar".

Adib Domingos Jatene é diretor geral do Instituto do Coração do Hospital das Clínicas da Faculdade de Medicina da Universidade de São Paulo. Foi secretário de Estado da Saúde e ocupou por duas vezes o Ministério da Saúde.

Conferência do Mês do Instituto de Estudos Avançados da USP feita pelo autor em 24 de março de 1998. Revisão de Melchíades Cunha Júnior. 